\title{
The Adsorption of Heavy Metal in Wastewater by Modified Chinese Walnut Shell
}

\author{
Chunguang $\mathrm{Yu}^{\mathrm{a}}$, Dayu Zheng \\ Harbin Commercial University, Harbin 150028, China. \\ aspringsun2015@qq.com
}

Keywords: Adsorbent; Wastewater; Chinese Walnut Shell

\begin{abstract}
This research use the modified Chinese Walnut Shell (MCWS) as adsorbent, purification for the wastewater from mechanical and electrical factory.It examines some factor to the effect such as adsorption time, mass, $\mathrm{pH}$ on the adsorption etc. The experiment of actual wastewater research shows that the adsorption rate of $\mathrm{Cr}^{6+}$ increased quickly after first $30 \mathrm{~min}$. After 90 minutes, the trend of adsorbttion rate of $\mathrm{Cd}^{2+}, \mathrm{Cu}^{2+}, \mathrm{Zn}^{2+}$ increase slowing, after 150 min to reach adsorption equilibrium. when MCWS adsorption dose for $3 \mathrm{~g} / \mathrm{L}$, removal rate of $\mathrm{Cu}^{2+}$ in practical wastewater can reach $89.21 \%$, the water quality after copper content meet the national second class pollutants maximum allowable emission concentration level 3 standards; Adsorption of $\mathrm{Cd}^{2+}$ removal rate reached $77.89 \%$, after the cadmium content in the water quality meet the national first class pollutant maximum allowable emission concentration standards; $\mathrm{Cr}^{6+}$ removal rate can reach $93.64 \%$, the cadmium content of maximum allowable emission concentration meet the national first class standards. So, the MCWS is a good adsorbent.
\end{abstract}

\section{Introduction}

Processing and product manufacturing is increasing along with the increase of the scope of human activity and intensity of human to heavy metal mining, smelting, so is dramatically increase the amount of waste water discharge ${ }^{[1]}$. From the perspective of the data of 2006 national environment statistical bulletin, the national industrial wastewater emissions of 265.2 billion tons, an increase of $10.2 \%$ over the previous year. Including cadmium, chromium, causing serious pollution of groundwater and surface water of heavy metal pollutants, the heavy metal pollutants in aquatic ecosystems cannot be biodegradable ${ }^{[2 ; 3]}$. Heavy metal not only can reside in the environment for hundreds of years or longer, and can enter the food chain transfer to the biological and human body ${ }^{[4]}$.

These toxic metal ions, not only for human health also has potential harm to other life. Toxic metal ions, which can lead to physical discomfort and sometimes cause fatal diseases including system irreversible damage to the body ${ }^{[5-7]}$. From the perspective of ecological toxicology, is one of the most dangerous metal mercury, lead, chromium and cadmium. In many instances, the effects of heavy metals to human has not yet been fully cognition. Metal ions in the environment through the biological accumulation and poisonous chemicals with biological amplification in the food chain. Therefore, the influence of their toxicity to higher trophic level is more significant. Nonferrous metals industry mining residue and waste water is the main source of heavy metals in the environment $^{[8]}$. Of heavy metals in common use, $\mathrm{Cr}, \mathrm{Cu}$, zinc, $\mathrm{Ni}$ and $\mathrm{V}$ of $\mathrm{Fe}$ and $\mathrm{Al}$ toxicity smaller than some. $\mathrm{Cu}$ is mainly used in electronics industry and the production of brass. Zinc is mainly used in zinc and alloy production, the half-life of cadmium is 10 to 30 years, it mainly in the human body

The half-life of cadmium is 10 to 30 years, which accumulated in the body mainly affect the kidney, bone, also can cause cancer, in electroplating, paint and battery industrial application is more and more widely in ${ }^{[9]}$. In fact, chromium compounds can harm kidneys and carcinogenic ${ }^{[10-12]}$. As a result of $\mathrm{Hg}$ and $\mathrm{Pb}$ toxicity is more and more attention, their widespread use in factories have been reduced or eliminated the ${ }^{[13 ; 14]}$. A set of processing waste water containing heavy metal waste water treatment plant equipment than the average amount of waste water treatment workshop of large 
amount of mixed wastewater. Heavy metal removal, relates to all aspects of the social development, must explore the effective methods to strengthen the management of heavy metal waste water.

Creatures and content of these elements in the human body also dramatically increased through the accumulation of a period of time, so that make the biological and human body some organizations and system produces pathological change ${ }^{[15]}$. common methods of industrial wastewater treatment at home and abroad are mainly chemical precipitation, ion exchange, membrane separation, electrolysis, oxidation, living creatures and adsorption, etc ${ }^{[16-18]}$. This paper use modified chinese walnut shell(MCWS) as adsorbent ,purifying industrial waste water.

\section{Materials and Methods}

The chinese walnut shell (CWS) was obtained from market in Harbin, China. CWS was modified by mixed $\mathrm{HCL}$ and $\mathrm{HNO}_{3}$ to 3:1, was washed by deionized water to remove dust and soluble material and then dried at $110^{\circ} \mathrm{C}$ for 2 hours. The dried CWS was crushed into a fine powder in a still mill. The resulting material was sifted through the 80 -mesh (180-um) standard sieve.

Experiment with the wastewater from an electric discharge of wastewater, including heavy metal element content as shown in table 1. In $100 \mathrm{ml}$ water and $2 \mathrm{~g} / \mathrm{L}$ pecan shell in a $150 \mathrm{ml}$ conical flask, with $0.1 \mathrm{M}$ hydrochloric acid and saturated calcium hydroxide to adjust $\mathrm{pH}$ value of wastewater, the set temperature of water bath temperature oscillator oscillation in a certain time. Various heavy metal ions adsorption rate is equal to the initial concentration and depth of wastewater purification treatment after divided by the difference between the initial concentration.

Table.1 Elements of the effiuent of metallurgicalindustry $(\mathrm{mg} / \mathrm{L})$

\begin{tabular}{lllllll}
\hline character & $\mathrm{pH}$ & $\mathrm{Cu}^{2+}$ & $\mathrm{Cd}^{2+}$ & $\mathrm{Cr}^{6+}$ & $\mathrm{Zn}^{2+}$ & $\mathrm{Pb}^{2+}$ \\
\hline contents & 3.62 & 18.56 & 0.48 & 5.00 & 10.32 & 6.47 \\
\hline
\end{tabular}

The concentration of ions in solution was determined by the Atomic Absorption Spectrometer.

Fourier Transform Infrared experiment was conducted to determine the surface functional groups of MCWS that might be relevant to ions adsorption. The $\mathrm{pH}$ of solution was measured with a Sartorius $\mathrm{pH}$ meter.

\section{Result and Disscuion}

\section{The effect of time}

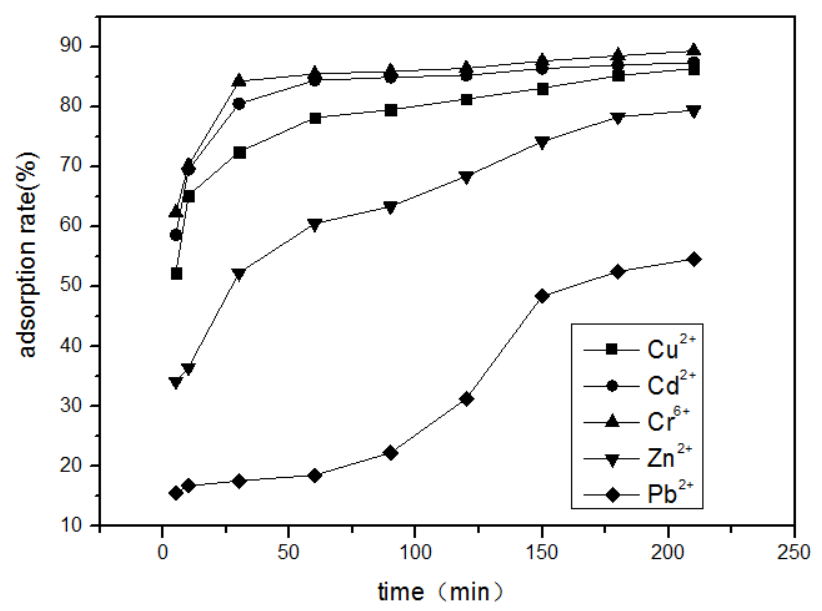

Fig.1 Effect of sorption time on removal of heavy metals unpon MCWS 
The influence of adsorption time to MCWS adsorption performance is shown in figure 1. Results show that MCWS on actual adsorption rate at the beginning of heavy metal waste water increases with the increase of adsorption time, after $30 \mathrm{~min}, \mathrm{Cr}^{6+}$ adsorption rate increases trend slowing, after 60 min to reach adsorption equilibrium. After 90 minutes, the adsorption rate of $\mathrm{Cd}^{2+}, \mathrm{Cu}^{2+}, \mathrm{Zn}^{2+}$ increase trend slowing, after $150 \mathrm{~min}$ to reach adsorption equilibrium. The tendency of increase with the $\mathrm{Pb}^{2+}$ slows after $150 \mathrm{~min}$, after $180 \mathrm{~min}$ to reach adsorption equilibrium.

\section{The effect of $\mathbf{p H}$}

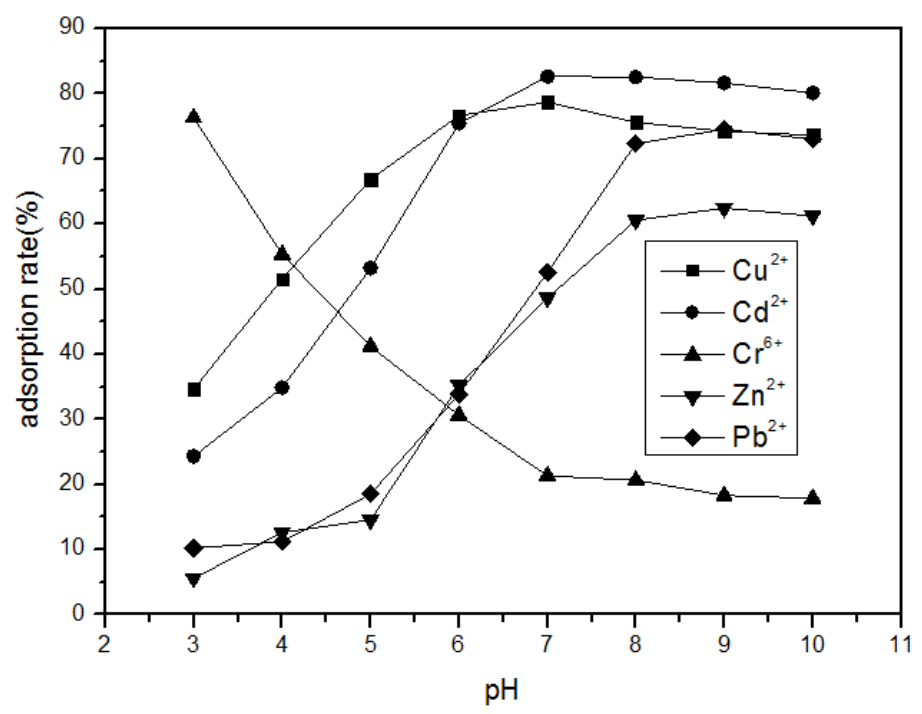

Fig.2 Effect of $\mathrm{pH}$ on removal heavy metal upon MCWS

Adsorption rate along with the change of $\mathrm{pH}$ value was shown in figure 2, $\mathrm{pH}$ range at 3.0-10.0, $\mathrm{Cu}^{2+}, \mathrm{Cd}^{2+}, \mathrm{Zn}^{2+}, \mathrm{Pb}^{2+}$ adsorption rate increases with the increase of $\mathrm{pH}$, when $\mathrm{pH}>8.0$, four kinds of heavy metal adsorption rate with the increase of $\mathrm{pH}$ basic remain unchanged; However for $\mathrm{Cd}^{2+}$ and $\mathrm{Cu}^{2+}$, the maximum adsorption rate at $\mathrm{pH} 7.0, \mathrm{pH}$ in less than 7.0 or greater than 7.0 the adsorption rate were slightly decreased. The maximum adsorption rate of $\mathrm{Pb}^{2+}$ and $\mathrm{Zn}^{2+}$ when $\mathrm{pH}$ was $8.0, \mathrm{pH}$ in the range of 8.0 to 10.0 , the adsorption rate changed little. $\mathrm{Cr}^{6+}$ compared to other three kinds of heavy metal ions, the adsorption rate decreased with the increase of $\mathrm{pH}$.

The effect of dose

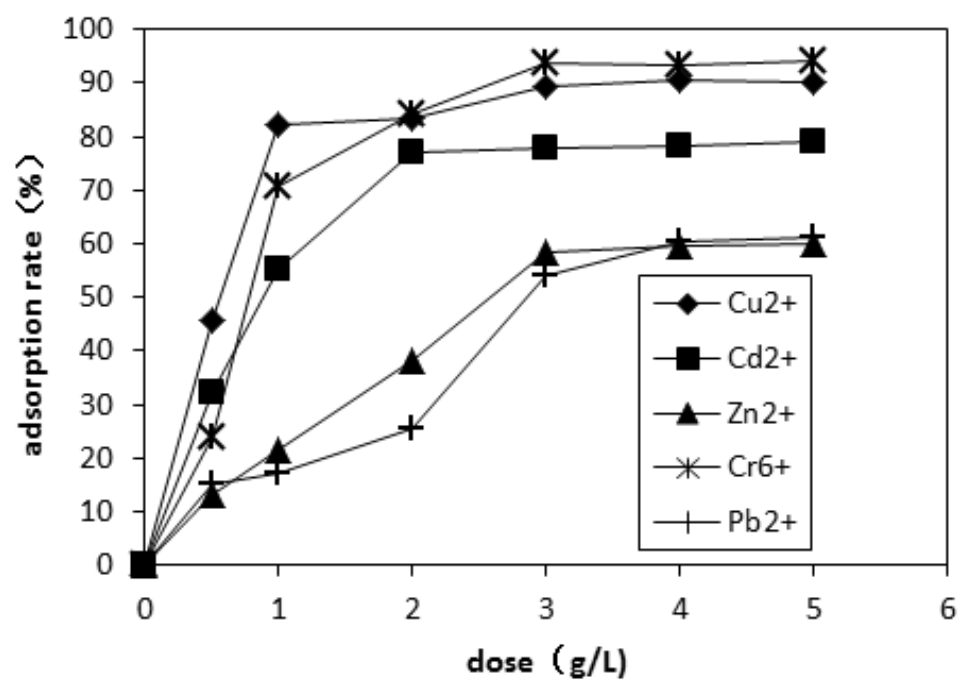

Fig.3 Effect of adsorbent dose for the remove of heavy metals from waste water

Figure 3 shows the effect of MCWS dose on adsorbent rate to the actual amount of heavy metal ions in waste water. It can be seen from the diagram in $100 \mathrm{ml}$ of $\mathrm{Cd}^{2+}, \mathrm{Cu}^{2+}, \mathrm{Zn}^{2+}, \mathrm{Cr}^{6+}$ and $\mathrm{Pb}^{2+}$ in 
waste water, when MCWS adsorption dose for $3 \mathrm{~g} / \mathrm{L}, \mathrm{Cu}^{2+}$ removal rate can reach $89.21 \%$, namely water samples of residual copper concentration of $1.86 \mathrm{mg} / \mathrm{L}$, the second type of pollutant is to meet the maximum allowable emission concentration level 3 standard total copper $(<2.0 \mathrm{mg} / \mathrm{L}) ; \mathrm{Cd}^{2+}$ removal rate reached $77.89 \%$, namely water samples of cadmium ion concentration is $0.1 \mathrm{mg} / \mathrm{L}$, maximum allowable emission concentration meet the national first class standards (cadmium $<0.1$ $\mathrm{mg} / \mathrm{L}$ ); $\mathrm{Cr}^{6+}$ removal rate can reach $93.64 \%$, the residual concentration of chromium in water samples is $0.381 \mathrm{mg} / \mathrm{L}$, maximum allowable emission concentration meet the national first class standards of hexavalent chromium $(<0.5 \mathrm{mg} / \mathrm{L})$.

\section{Conclusion}

The experiment of actual wastewater research shows that the adsorption rate of $\mathrm{Cr}^{6+}$ increased quickly after first $30 \mathrm{~min}, \mathrm{Cr}^{6+}$ adsorption rate increases trend slowing after $60 \mathrm{~min}$ to reach adsorption equilibrium. After 90 minutes, the trend of adsorbttion rate of $\mathrm{Cd}^{2+}, \mathrm{Cu}^{2+}, \mathrm{Zn}^{2+}$ increase slowing, after 150 min to reach adsorption equilibrium. The tendency of increase with the $\mathrm{Pb}^{2+} \mathrm{slow}$ after $150 \mathrm{~min}$, after $180 \mathrm{~min}$ to reach adsorption equilibrium.when MCWS adsorption dose for $3 \mathrm{~g} / \mathrm{L}$, removal rate of $\mathrm{Cu}^{2+}$ in practical wastewater can reach $89.21 \%$, the water quality after copper content meet the national second class pollutants maximum allowable emission concentration level 3 standards; Adsorption of $\mathrm{Cd}^{2+}$ removal rate reached $77.89 \%$, after the cadmium content in the water quality meet the national first class pollutant maximum allowable emission concentration standards; $\mathrm{Cr}^{6+}$ removal rate can reach $93.64 \%$, the cadmium content of maximum allowable emission concentration meet the national first class standards.

\section{Acknowledgements}

The authors thank The Doctor Research Projects of Harbin commercial university (Project Number: 13DL009) for the financial support to this project.

\section{Reference}

[1] Lloyd-Jones P J, Rangel-Mendez J R, Streat M. Sorption of cadmium using a natural biosorbent and activated carbon[J]. Hazards Xvi: Analysing the Past, Planning the Future, 2001, (148): 847-866

[2] Dong X, Wang C, Li H, et al. The sorption of heavy metals on thermally treated sediments with high organic matter content[J]. Bioresource Technology, 2014, 160(0): 123-128.

[3] Arenas-Lago D, Andrade M L, Lago-Vila M, et al. Sequential extraction of heavy metals in soils from a copper mine: Distribution in geochemical fractions[J]. Geoderma, 2014, 230-231(0): 108-118.

[4] Boamah P O, Huang Y, Hua M, et al. Sorption of heavy metal ions onto carboxylate chitosan derivatives-A mini-review[J]. Ecotoxicology and Environmental Safety, 2015, 116(0): 113-120.

[5] Athanasekou C P, Romanos G E, Kordatos K, et al. Grafting of alginates on UF/NF ceramic membranes for wastewater treatment[J]. Journal of hazardous materials, 2010, 182(1-3): 611-623.

[6] Morico K, Moore B, Novotny J. Electronics and Metal Finishing Processing[J]. Water Environment Research, 2009, 81(10): 1606-1614.

[7] Perez-Marin A B, Ballester A, Gonzalez F, et al. Study of cadmium, zinc and lead biosorption by orange wastes using the subsequent addition method[J]. Bioresource Technology, 2008, 99(17): 8101-8106.

[8] Rao G P, Lu C, Su F. Sorption of divalent metal ions from aqueous solution by carbon nanotubes: A review[J]. Separation and Purification Technology, 2007, 58(1): 224-231. 
[9] Shin E W, Karthikeyan K G, Chung J S, et al. Different cadmium adsorption behavior of juniper wood and bark sorbents[M]. 2005: 434-438.

[10] Tamilselvan N, Saurav K, Kannabiran K. Biosorption of Cr (VI), Cr (III), Pb (II) and Cd (II) from aqueous solutions by Sargassum wightii and Caulerpa racemosa algal biomass[J]. Journal of Ocean University of China, 2012, 11(1): 52-58.

[11] Singh J, Ali A. Kinetics, Thermodynamics and Breakthrough Studies of Biosorption of Cr (VI) using Arachis hypogea Shell Powder[J]. Research Journal of Chemistry and Environment, 2012, 16(1): 69-79.

[12] San N O, Donmez G. Biosorption of chromium(VI), nickel(II) and Remazol Blue by Rhodotorula muciloginosa biomass[J]. Water Science and Technology, 2012, 65(3): 471-477.

[13] Wang X S, Li F Y, He W, et al. Hg(II) Removal from Aqueous Solutions by Bacillus subtilis Biomass[J]. Clean-Soil Air Water, 2010, 38(1): 44-48.

[14] Wang C, Zhao J, Wang Y, et al. Sensitive Hg (II) ion detection by fluorescent multilayer films fabricated with quantum dots[J]. Sensors and Actuators B-Chemical, 2009, 139(2): 476-482.

[15] Iwahori K, Watanabe J-I, Tani Y, et al. Removal of heavy metal cations by biogenic magnetite nanoparticles produced in $\mathrm{Fe}(\mathrm{III})$-reducing microbial enrichment cultures[J]. Journal of Bioscience and Bioengineering, 2014, 117(3): 333-335.

[16] Machado M D, Soares E V, Soares H M V M. Removal of heavy metals using a brewer's yeast strain of Saccharomyces cerevisiae: application to the treatment of real electroplating effluents containing multielements[J]. Journal of Chemical Technology and Biotechnology, 2010, 85(10): 1353-1360.

[17] Xiao H, Böttcher J, Utermann J. Evaluation of field-scale variability of heavy metal sorption in soils by scale factors - Scaling approach and statistical analysis[J]. Geoderma, 2015, 241-242(0): 115-125.

[18] Yousef R I, El-Eswed B, Al-Muhtaseb A H. Adsorption characteristics of natural zeolites as solid adsorbents for phenol removal from aqueous solutions: Kinetics, mechanism, and thermodynamics studies[J]. Chemical Engineering Journal, 2011, 171(3): 1143-1149. 